\title{
Reactive Power Management in an Offshore AC Network having Multiple Voltage Source Converters
}

\author{
Muhammad Raza ${ }^{\mathrm{a}, *}$, Carlos Collados ${ }^{\mathrm{a}}$, Oriol Gomis-Bellmunt ${ }^{\mathrm{a}}$ \\ ${ }^{a}$ Centre d'Innovació Tecnològica en Convertidors Estàtics i Accionaments, Departament \\ d'Enginyeria Elèctrica, Universitat Politècnica de Catalunya, Barcelona Spain
}

\begin{abstract}
Many offshore wind power plants are being developed every year at North and Baltic Sea. From the prospective of environment and integrated European power, combined power transmission from several offshore wind power plants using VSC-HVDC transmission system to different onshore grids are suitable instead of connecting each wind power plants individually. Offshore $\mathrm{AC}$ hub is beneficial for the wind power plants that are far from shore but close to each other within the vicinity of $20 \mathrm{~km}$. This paper presents a method of controlling reactive power flow in the offshore AC grid to minimize the power losses and voltage deviation. In the proposed scheme, offshore grid frequency and voltage are controlled through more than one converters. Using frequency and voltage droop scheme, the active and reactive power sharing is achieved among converters. Furthermore, the optimization algorithm also provides the set points for wind power plants to contribute in the management of reactive power flow.
\end{abstract}

Keywords: Droop control, multi-objective optimization, offshore wind power plants, offshore AC hub, reactive power management, VSC-HVDC transmission system

\footnotetext{
*Corresponding author

Email addresses: muhammad.raza@citcea.upc.edu (Muhammad Raza), carlos.collados@citcea.upc.edu (Carlos Collados), oriol.gomis@citcea.upc.edu (Oriol Gomis-Bellmunt)
} 


\section{Introduction}

Renewable generations are becoming universally adopted primary source of energy. A breakthrough in advanced power transmission technology, specially in the power electronics devices, has enabled the installation of renewable generation units at remote locations. The wind energy has been a main focus in the last decade particularly at offshore comparatively to other renewable sources. Up to the mid of 2016, 3, 344 offshore wind turbines with a combined capacity of 11, $538 \mathrm{MW}$ have been installed in European waters [1, 2].

The most common export system for the offshore wind energy to onshore grid is the high voltage alternating current (HVAC) cable system, typically at the voltage level of $150 \mathrm{kV}$. The HVAC export system is a well established technology. However, the HVAC cables have high effective capacitance that limits the transmission of large active power over the long distance, typically limited up to $90 \mathrm{~km}$ for $100 \mathrm{MW}$ [3]. A voltage source converter (VSC) based high voltage direct current (HVDC) transmission system has eliminated the power export limitation imposed by cable capacitive effect, and it has the ability to create the offshore grid [4-6]. Many experts are foreseeing the need of having offshore grid for better trade and integration of large offshore wind energy generation in Europe [7, 8]. An offshore grid would link several offshore wind power plants with different countries. In [9], the impact of an offshore grid on the European energy market has been studied considering several technical concepts for grid connection. A new concept of 'hub and spoke' transmission system for the interconnected North Sea is proposed by Tennets [10]. In this concept, an artificial island called 'hub' will be build in center of different offshore wind power plants that are far from the shore. Offshore wind power plants and onshore grids will be connected with export system called as 'spoke'. For wind power plants connection with the hub, the export system will be high voltage alternating current (HVAC) cables system since the distance will be short, and the installation is simple and cheap. For onshore connection with the hub, the export system will be VSC-HVDC transmission system as the distances of countries from the island are longer. Once build, up to $100 \mathrm{GW}$ or more of offshore wind energy is expected to be connected via this island.

There are several options under investigation for the formation of the offshore grid [11]. The interconnection between onshore grids via multi-terminal (MT) HVDC system requires the DC circuit breaker which may increases the overall system development cost $[12,13]$. Further, the mesh DC network 
may also need the selectivity and reliability at the level similar to distribution network at onshore. The DC protection system is complex compare to AC since the require fault interruption time is less in the DC network and there is no zero crossing in the DC current. Another approach to interconnects onshore grids is through offshore $\mathrm{AC}$ hub using point-to-point VSC-HVDC transmission topology. In this way, the DC circuit breaker is not required, and the DC fault protection can be achieved using AC circuit breakers and by opening IGBTs valves. Offshore AC hub is the network of medium or high voltage AC cables that interconnects several offshore wind power plants with each other [14]. Wind power plant distance up to $20 \mathrm{~km}$ from the offshore $\mathrm{AC}$ hub is considered economical [15]. To operate the offshore AC network or hub, the VSCs of HVDC transmission system controls the voltage and frequency as the primary sources and they behave as slack sources in the network [16-18]. The distribution of the total power in the network among the HVDC transmission system can be controlled by applying frequency and voltage droop schemes in the VSCs [14]. The advantage of droop scheme is to have multiple distributed slack sources in the network, and communication between VSC-HVDC transmission system is not required for power sharing during normal operation as well as in the failure of any transmission system. However, the parallel operation of the VSCs require the impose frequencies to converge at the same equilibrium point to achieve stability in the system. The dynamic and stability aspects of parallel operating VSC to control offshore AC network are discussed in [19]. The study perform in [19] provide the boundaries limits of frequency and voltage droop gains for stable operation which can be applied to determine the optimum steady-state operating points.

Reactive power management is an important factor in minimizing losses in the network with respect to the active power dispatch by the wind turbines [20]. Traditionally, reactive power management is addressed as an optimization problem and the solution is found by solving an optimal power flow algorithm (OPF) [21, 22]. The solution of OPF algorithm provides the reactive power set-points for wind turbines with respect to wind active power in-feed based on minimization criteria define as an objective function in the algorithm, such as active power loss, voltage deviation, cost etc. Multiobjective optimization technique compared to single objective offer advantage in term of providing solution with respect to the weight of multiple loss function criteria in order to operate the network more effectively [21, 23-26]. At present, most of the offshore wind power plants are connected to a single 
onshore grid. In future projects such as Kriegers flak, there will be several wind power plants connected to different onshore grids [27]. This will require diverse approach to optimize the network operation. Optimal network operation through only wind turbines reactive power dispatch will not be sufficient due to the active power trade operation among onshore grids. This has introduced the additional constraints compare to traditional offshore wind farm network in which all produce wind power received at single onshore grid. For the offshore $\mathrm{AC}$ network having multiple wind power plants interconnection, the VSC based HVDC transmission system will be suitable as an export system due to its ability to control the distribution of power flow in the offshore network [28]. The frequency and voltage droop schemes provide additional degree of freedom to control the active and reactive power flow. This further allows to optimize the network operation according to the wind dispatch and trade requirement.

Currently, no such study is performed for the optimization of the offshore $\mathrm{AC}$ network that have parallel connected VSC systems. In this paper, a method of reactive power management has been proposed for an offshore AC network using multi-objective optimization technique. This paper is an extension of a research work presented in [29]. The optimization problem is solved using interior point method. The solution of the algorithm provides the reactive power set points of each wind power plant and reactive power contribution from each VSC-HVDC transmission system according to the net wind power generation. The paper also address the droop gains selection method considering the network long-term voltage stability. The rest of the paper is organized as follows: Section II explains the configuration of the offshore AC network and the operation of the VSC-HVDC transmission system, in Section III an optimization problem is formulated, the analysis of the optimization results have been performed in Section IV, and Section V conclude this paper.

\section{System Configuration}

The application of the proposed optimization method is demonstrated on the network shown in Fig. 1. The offshore AC network have four wind power plants connected together in a mesh configuration using HVAC cable at the voltage level of $150 \mathrm{kV}$. Power from this AC network is supplied to two different onshore grids using point-to-point VSC-HVDC transmission systems. The layout of the individual wind power plants is not the focus 


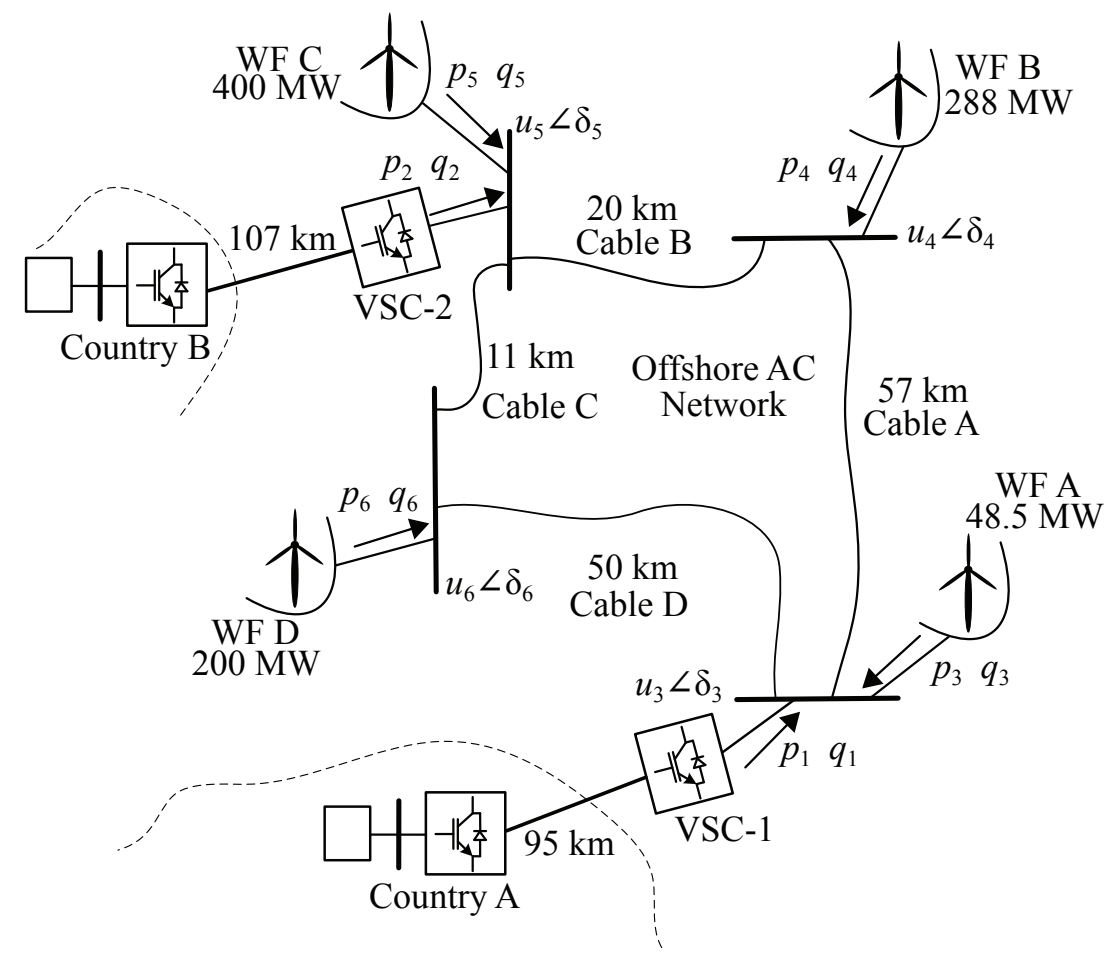

Figure 1: Configuration of offshore AC network interconnecting two onshore grid using VSC-HVDC system.

of this research. It is considered that the wind power plants contain Type IV wind turbines which control active and reactive power individually and able to provide reactive power support within its operating capability at the connection point. Further, it is also assumed that the internal layout of wind power plants are in radial or radial-ring configuration, so that active power flows only from wind turbines to offshore AC network. The network parameters are derived from the publicly available data of Kriegers flak and EnBW Baltic 1 and 2 offshore wind power plants. The parameters are not exactly the same however they resembles most of the configuration. Such as WF $\mathrm{A}$ and $\mathrm{B}$ resembles the Baltic 1 and 2 offshore wind power plant power rating. WF $\mathrm{C}$ and $\mathrm{D}$ resembles the Kriegers flak offshore wind power plants. Although in the real project both offshore wind power plants are connected to onshore grid via HVAC cables i.e. $150 \mathrm{kV}$ for Baltic 1 and 2 offshore wind power plants and $245 \mathrm{kV}$ for Kriegers flak offshore wind power plant, it is assumed in the study that these connections are made via VSC-HVDC 
Table 1: Offshore network impedance for OPF

\begin{tabular}{lccc}
\hline Name & Resistance & Inductance & Capacitance \\
\hline AC Cable & $0.0151 \Omega / \mathrm{km}$ & $0.118 \mathrm{mH} / \mathrm{km}$ & $0.24 \mu \mathrm{F} / \mathrm{km}$ \\
Transformer $^{\mathrm{a}}$ & $0.099 \Omega$ & $17.2 \mathrm{mH}$ & - \\
Filter Capacitor $^{\mathrm{a}}$ & - & - & $6.85 \mu \mathrm{F}$ \\
DC Cable & $0.019 \Omega / \mathrm{km}$ & - & - \\
\hline
\end{tabular}

${ }^{\text {a }}$ refer to $150 \mathrm{kV}$ level.

transmission system. The maximum accumulated wind power into offshore AC network is $936.5 \mathrm{MW}(1.873 \mathrm{p.u})$. The capacity of each transmission system is $655.55 \mathrm{MW}(1.31 \mathrm{p} . \mathrm{u})$. Thus, the maximum power that can be transferred by one VSC-HVDC system is $0.7 \mathrm{p} . \mathrm{u}$. The base values for system analysis are $500 \mathrm{MVA}, 150 \mathrm{kV}$, and $50 \mathrm{~Hz}$. The impedances of the network for the OPF algorithm are given in Table $1[30,31]$.

The onshore side converter of the VSC-HVDC system controls the DC voltage and they are synchronized with the onshore grid frequency. The design procedure for a DC voltage control is given in [32]. At the steadystate, the voltage at the onshore converter DC busbar is controlled to $1.0 \mathrm{p} . \mathrm{u}$ ergo making it a slack bus in the DC network. The offshore side converters of VSC-HVDC system operates in grid-forming mode and impose the frequency and voltage on the offshore network. The control system of grid-forming VSC is shown in Fig. 2. The VSCs behave as a voltage controlled voltage source in the offshore AC network which controls the voltage at filter busbar. The VSC control system is designed in $d q 0$ voltage synchronous rotating frame and it has three level of control system i.e current control, voltage control, and network level control.

\subsection{Current Control}

The current closed loop control ensure the fast response of the VSC against any abrupt changes in power, and it improves the dynamic behavior of the system. The current controller consists of current $d$ - and $q$-components decoupling scheme and proportional-plus-integral (PI) regulator. The current decoupling scheme eliminates the interaction of both $d q$-components and the controller parameters can be designed using linear control theory [32]. The first order closed loop current response can be achieved by selecting PI 


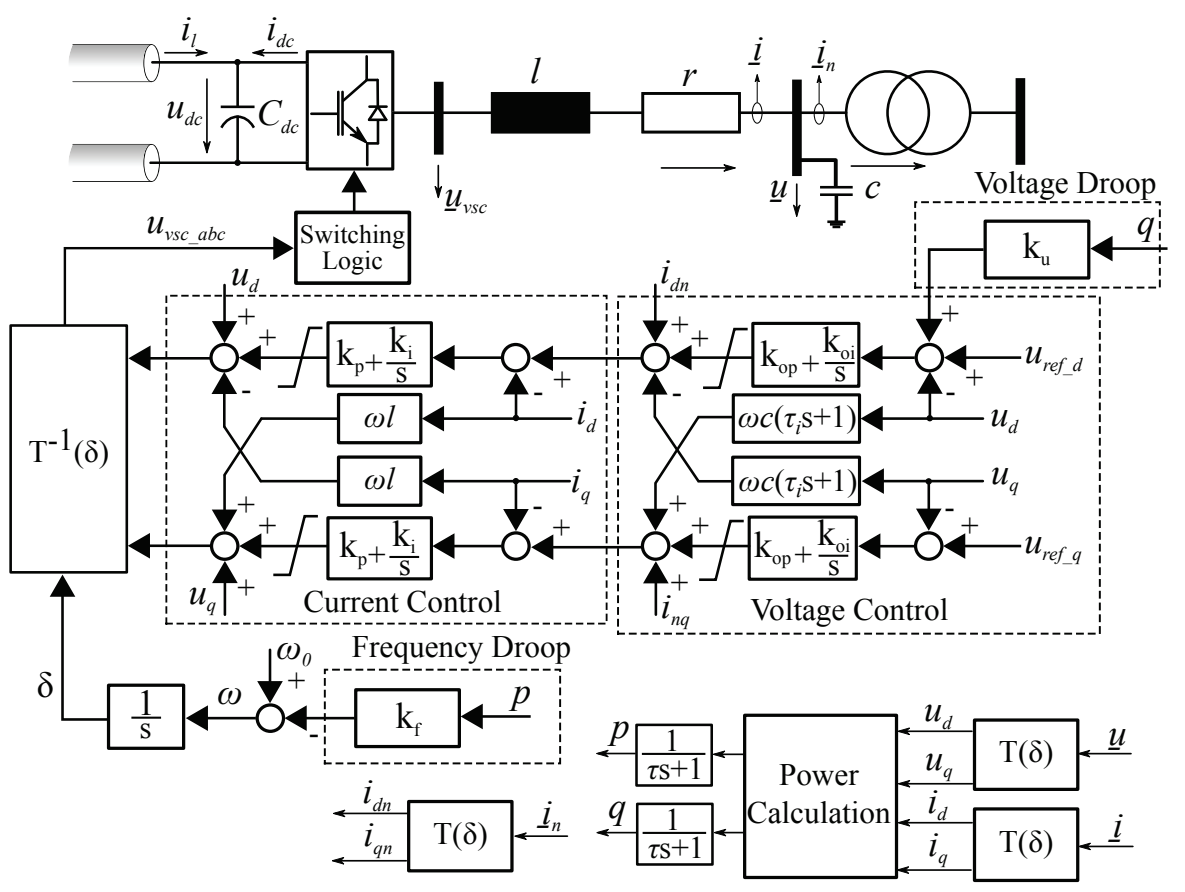

Figure 2: Voltage source converter control system for the offshore AC network.

controller gain values using internal model control (IMC) method. The PI gains can be calculated using (1). Both PI controller gains of current $d q$ components have same values.

$$
k_{p}=\frac{l}{\tau_{i}}, \quad k_{i}=\frac{r}{\tau_{i}}
$$

Here, $k_{p}$ is the proportional gain, $k_{i}$ is the integral gain, $\tau_{i}$ is the desired closed loop current time constant, $r$ is series reactor resistance, and $l$ is the series reactor inductance. The current $d q$ - components reference command signals are set by voltage controller.

\subsection{Voltage Control}

The voltage control loop imposes the voltage at the filter busbar and make VSC behavior as a voltage source. The voltage controller consists of voltage $d$ - and $q$-components decoupling scheme and proportional-plusintegral regulator for zero steady-state error. The closed loop characteristic equation of the voltage control is of $3^{\text {rd }}$ order polynomial form and the voltage 
PI controller gains must be selected according to the condition given in (2) to ensure system stability. The controller gains can be tuned using root locus method to achieve desire performance. The detail of the control system design is explained in [32].

$$
\begin{gathered}
u=\frac{\left(k_{o p} s+k_{o i}\right) u_{r e f}(s)+\left(\tau_{i} s^{2}\right) i_{n}(s)}{\tau_{i} c s^{3}+c s^{2}+k_{o p} s+k_{o i}} \\
0<k_{o i}, \quad \text { and } \tau_{i} k_{o i}<k_{o p}
\end{gathered}
$$

Here, $k_{o i}$ and $k_{o p}$ are the proportional and integral gains of the voltage controller, $c$ is the filter capacitance, $u_{r e f}(s)$ is the reference voltage set-point, and $i_{n}(s)$ is the network current.

In the $d q 0$ rotating frame, the voltage set-points are the rated voltage without voltage droop scheme, and they are defined as $u_{r e f_{-} d}+j u_{r e f_{-} q}=$ $1.0+j 0.0$ p.u (see Fig. 2).

\subsection{Network Level Control}

The VSCs of HVDC transmission system in the offshore AC network controls the frequency of the network directly (no inertia exists), in contrary of synchronous machine control principle in which network frequency is controlled by balancing electrical power with mechanical power. It is known that the unbalance in the mechanical and electrical active power changes the rotation speed of the synchronous machine that consequently affect the network frequency. But the network containing only VSCs do not have this natural connection between frequency and active power. For such a network, a frequency droop scheme is preferable to create the link between frequency and power as illustrated in Fig. 3a. By having different slope of the powerfrequency curve, active power can be shared between $\mathrm{AC}$ grids according to the operator requirement.

Furthermore, the offshore converters VSC-1 and VSC-2 both control the different busbar voltages. A voltage droop scheme can be applied to share the reactive power among the VSC-HVDC transmission system as illustrated in Fig. 3b. Unlike frequency of the network, the voltages at the controlling busbars do not converge at the same equilibrium point due to the network impedance. The difference of the voltage enables the control on the reactive power contribution by each VSC and the reactive power management in the network can be done by adjusting the slope of the voltage droop gain [29]. The dynamic and stability impact of the voltage and frequency droop 


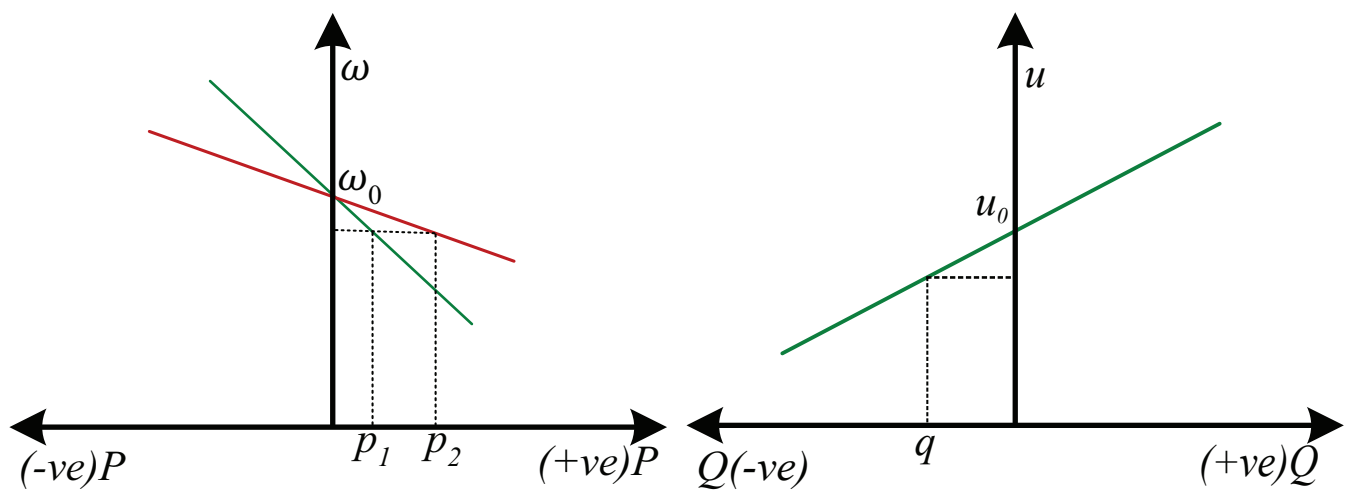

(a) Power-Frequency Response

(b) Power-Voltage Response

Figure 3: Droop characteristic of voltage source converter to control frequency and voltage of the offshore AC network.

schemes is addressed in [19]. In this paper, the droop gains are determined according to the steady-state operational requirements by defining offshore $\mathrm{AC}$ network as an optimization problem.

\section{Optimization Problem}

The management of the reactive power is an important factor for minimizing the losses of the network. The more active elements that control the voltage in the network, the more flexibility in managing the reactive power. Normally, an optimization problem consists of the system constraints and the objective functions that are required to be satisfied to have the optimal solution. The power flow optimization is a nonlinear non-convex problem and it has large number of local minima. A local minima can be designated as a global minima within the closed interval define by the constraints and boundaries. The system constraints and limits ensure that the same local minima is found at different initial values for the given predefined conditions and sets of inputs or get no solution at all. In this paper, interior-point method using MATLAB function 'fmincon' is applied for finding solution using multiple initial values. The problem has been implemented using sets of non-linear equations that are derived as follows:

\subsection{Constraints}

A system configuration and the control conditions are defined as nonlinear equalities and inequalities constraints for the formulation of an optimization 
problem. These constraints consist of AC and DC network topologies, VSCs droop control equations, power sharing criteria, and boundary limits.

\subsubsection{Offshore $A C$ and DC Network Topology}

A network topology is an equality constraint and it is usually defined by the power flow equations. The power flow equations for the $\mathrm{AC}$ network are defined using (3).

$$
\begin{aligned}
& p_{l}=u_{l} \sum_{m=1}^{n} u_{m}\left(g_{l m} \cos \left(\delta_{l}-\delta_{m}\right)+b_{l m} \sin \left(\delta_{l}-\delta_{m}\right)\right) \\
& q_{l}=u_{l} \sum_{m=1}^{n} u_{m}\left(g_{l m} \sin \left(\delta_{l}-\delta_{m}\right)-b_{l m} \cos \left(\delta_{l}-\delta_{m}\right)\right)
\end{aligned}
$$

Where, $n$ is the total number of $\mathrm{AC}$ busbar in the offshore network, $p_{l}$ and $q_{l}$ are the active and reactive power at the $l^{\text {th }} \mathrm{AC}$ bus respectively, $u_{l}$ and $u_{m}$ are the $\mathrm{AC}$ busbar voltages, $\delta_{l}$ and $\delta_{m}$ are the voltage angle of the AC busbar, and $g_{l m}$ and $b_{l m}$ are the conductance and susceptance of the branch elements in the AC network.

There are two separate DC networks in the point-to-point configuration in the system. According to the power flow principle, the onshore converter side DC busbar is defined as the slack bus. The offshore converter side DC busbar is defined as the load bus whose power is defined by the offshore AC network. The DC active power at any $i^{\text {th }}$ busbar can be defined using (4).

$$
P_{i}=U_{i} \sum_{j=1}^{k} U_{j} G_{i j}
$$

Here, $k$ is the total number of DC busbar in a DC network and it is equal to 2 for each VSC-HVDC transmission system configured in the point-topoint topology. $P_{i}$ is the DC active power at the $i^{t h}$ busbar, $U_{i}$ and $U_{j}$ are the DC voltages, and $G_{i j}$ is the conductance of the branch elements in the $\mathrm{DC}$ network. The link between the $\mathrm{AC}$ and $\mathrm{DC}$ power flow is established by defining active power loss function as (5).

$$
p_{v s c}+P_{d c}+P_{l o s s}=0
$$

Here, $p_{v s c}$ is the AC active power of the offshore converter, $P_{d c}$ is the DC active power at the offshore converter, and $P_{\text {loss }}$ is the losses in the converter. The per unit converter station loss $\left(P_{\text {loss }}\right)$ is calculated using 
quadratic function depending on the converter current $\left(i_{v s c}\right)$ as expressed by (6).

$$
\begin{aligned}
P_{l o s s} & =a+b \cdot i_{v s c}+c \cdot i_{v s c}^{2} \\
i_{v s c} & =\frac{\sqrt{p_{v s c}^{2}+q_{v s c}^{2}}}{u_{v s c}}
\end{aligned}
$$

Here, $q_{v s c}$ is the reactive power of the offshore converter, $u_{v s c}$ is the offshore converter busbar voltage, $a=11.033 \times 10^{-3} \mathrm{p} . \mathrm{u}$ is a no-load coefficient, $b=3.464 \times 10^{-3} \mathrm{p} . \mathrm{u}$ is the voltage drop coefficient, and $c=4.4 \times 10^{-3} \mathrm{p} . \mathrm{u}$ is the ohmic loss coefficient. The value of these power loss coefficients are derived from [33].

\subsubsection{Voltage and Frequency Droop Control of the VSC-HVDC}

The VSCs control the voltage at the filter bus, and this bus act as a slack bus in the AC network. In the OPF algorithm, VSCs consume all power injected by the wind power plants. Without droop control, the active and reactive powers through VSCs flow according to the impedance of the network. For the network shown in Fig. 1, the power sharing between VSC-1 and VSC-2 can be achieved by applying voltage and frequency droop schemes as expressed by (7), .

$$
\begin{aligned}
& u_{1}=u_{0}+k_{u 1} \cdot q_{1} \\
& u_{2}=u_{0}+k_{u 2} \cdot q_{2} \\
& \omega_{1}=\omega_{0}-k_{f 1} \cdot p_{1} \\
& \omega_{2}=\omega_{0}-k_{f 2} \cdot p_{2}
\end{aligned}
$$

Here, $u_{1}$ and $u_{2}$ are VSC- 1 and VSC-2 filter bus voltages, $\omega_{1}$ and $\omega_{2}$ are the frequencies imposed by VSC-1 and VSC-2, $p_{1}$ and $q_{1}$ are the active and reactive power flow through the $\mathrm{VSC}-1$, and $p_{2}$ and $q_{2}$ are the active and reactive power of VSC-2. The rated bus voltage is set-points of VSC-1, and VSC-2 i.e $u_{\text {ref_d }}=u_{0}=1.0$ p.u.

At steady-state, both VSCs should impose the same frequency therefore the resultant frequency at steady state can be calculated using (8).

$$
\begin{aligned}
& \omega=\omega_{1}=\omega_{2} \\
& \omega=\omega_{0}-\frac{k_{f 1} k_{f 2}}{k_{f 1}+k_{f 2}} \cdot\left(p_{1}+p_{2}\right)
\end{aligned}
$$

Unlike frequency, voltages applied by the VSCs are not linked at the same level due to presence of the impedance between them, therefore, network 
voltages steady state values will be known after the power flow solution of the network is found. The VSCs droop control equations are applied as equality constraint in the OPF algorithm.

\subsubsection{Power Sharing Criteria}

The OPF algorithm provide the droop gains value by applying additional power sharing criteria. The power sharing could be a transmission system operator requirement which defines the percentage of the total wind power to be transferred through each VSC-HVDC system.

Consider $\alpha$ as an active power contribution of VSC-2. Thus, the VSC-2 active power $\left(p_{2}\right)$ can be written in term of $\alpha$ and the net active power $\left(p_{1}+p_{2}\right)$ received by both converters using (9). The active power contribution factor of VSC-1 will then be $1-\alpha$.

$$
p_{2}=\alpha \cdot\left(p_{1}+p_{2}\right)
$$

Using (7), (8), and (9), the relationship between $\alpha$ and frequency droop gains can be defined as (10).

$$
\alpha \cdot\left(k_{f 1}+k_{f 2}\right)-k_{f 1}=0
$$

Similarly, consider $\beta$ as a reactive power contribution factor of VSC-2. Using (11), the reactive power flow of VSC-2 can be expressed in term of the reactive power contribution factor and the net reactive power generated by both converters combined.

$$
q_{2}=\beta \cdot\left(q_{1}+q_{2}\right)
$$

Furthermore, the voltage droop scheme increases the slack bus voltage proportional to the reactive flowing through it, hereby generates additional reactive power. The impact of the voltage droop on the network can be understood by analyzing the change it cause in the reactive power at the load bus. Consider that the load bus is directly connected with a VSC reference bus thus the reactive power flow can be expressed separately as (12) for the branch that is connected with the VSC.

$$
\begin{aligned}
q_{l}-u_{l} \sum_{\substack{m=1 \\
m \neq i}}^{n-1} u_{m}\left\{g_{l m} \sin \left(\Delta \delta_{l m}\right)-b_{l m} \cos \left(\Delta \delta_{l m}\right)\right\} \\
\quad-u_{l} u_{i}\left\{g_{l i} \sin \left(\Delta \delta_{l i}\right)-b_{l i} \cos \left(\Delta \delta_{l i}\right)\right\}=0
\end{aligned}
$$


Here, $i$ is the index of the VSC reference bus (i.e filter bus) at which the droop scheme has been applied as $u_{i}=u_{0}+k_{u_{i} i} q_{i}$. By substituting the voltage droop equation in (12), the reactive power mismatch equation of the load bus can be expressed as (13).

$$
\underbrace{q_{l}-u_{l} \sum_{\substack{m=1 \\ m \neq i}}^{n-1} u_{m} h_{l m}-u_{l} u_{0} h_{l i}}_{k_{u_{-} i}=0} \underbrace{-u_{l} k_{u_{-i} i} q_{i} h_{l i}}_{\Delta q_{k_{-i}}}=0
$$

Here, $h_{l m}=g_{l m} \sin \left(\Delta \delta_{l m}\right)-b_{l m} \cos \left(\Delta \delta_{l m}\right)$, and $h_{l i}=g_{l i} \sin \left(\Delta \delta_{l i}\right)-$ $b_{l i} \cos \left(\Delta \delta_{l i}\right)$. The first three term in the above equation are the mismatch reactive power when there is no droop control. The droop control create the change in the mismatch power depending on the droop gains and the reactive power flowing through the VSC. In case of only one VSC in the offshore network, this additional reactive power largely impact on the network voltages since there is no sources other than cable capacitance to absorb it. However, the multiple grid forming VSCs in the offshore AC network can exchange this additional reactive power for balancing and to reduces its impact on the network voltages. To achieved this, the criteria given in (14) can be applied to determine the droop gains.

$$
\begin{gathered}
\Delta q_{k_{-} 1}+\Delta q_{k_{-} 2}+\cdots+\Delta q_{k_{-} z}=0 \\
\sum_{i=1}^{z} \sum_{l=1}^{y} u_{l} k_{u_{-} i} q_{i} h_{l i}=0 \quad \forall i, l: i \neq l
\end{gathered}
$$

Here, $z$ is the total number of grid forming VSCs in the offshore AC network, $y$ is the total number of load buses connected with the $i^{\text {th }}$ VSC.

\subsubsection{Operational Boundary Limits}

The operational limits are applied by defining inequality constraints. These boundaries limits are based on the general requirements of Tennets grid codes [34]. The voltage magnitude limits are applied to keep the voltage deviation less than $10 \%$. The voltage phase angle limits are set to cover the full range of power flow through the branches. The active power rating of a single VSC-HVDC transmission system is less than the sum of all wind power plants active power rating. The Kriegers flak wind power plants combine power is $600 \mathrm{MW}$. In order to illustrate the application of export capability 
from Baltic 1 and 2, a single VSC-HVDC transmission line capacity is selected as $655.55 \mathrm{MW}$ which is $70 \%$ of combined wind power plants capacity. The maximum VSC reactive power support is set to have 0.9564 power factor which is within the limits of grids codes. The frequencies range for continue operation defined in grid codes are set as the frequency boundaries limit i.e. 1.004 p.u $(50.2 \mathrm{~Hz})$ and 0.98 p.u $(49 \mathrm{~Hz})$. The frequency and voltage droop gains boundaries are calculated by performing small signal analysis using method given in [19]. The reactive power sharing factor $(\beta)$ should be in the range of 0.0 to 1.0. Note that the sum of reactive power sharing factor of all VSC-HVDC transmission system should be equal to 1.0. The wind power plants reactive power limits are applied to enforce the power factor within the limits defined in grid codes and it is based on each wind power plants active power rating. The power factor of $0.97,0.96,0.93$, and 0.92 are considered for WF-A, WF-B, WF-C, and WF-D, respectively. Based on these criteria, the output vector variables are bounded between upper and lower limits as (15).

$$
\begin{aligned}
0.90 & \leq u \leq 1.10 \\
-\pi & \leq \delta \leq \pi \\
-1.31 & \leq p_{v s c} \leq 1.31 \\
-0.4 & \leq q_{v s c} \leq 0.4 \\
0.98 & \leq \omega \leq 1.004 \\
0 & \leq k_{f} \leq 0.01 \\
-0.1 & \leq k_{u} \leq 0.1 \\
0 & \leq \beta \leq 1.0 \\
-0.0243 & \leq q_{3} \leq 0.0243 \\
-0.168 & \leq q_{4} \leq 0.168 \\
-0.281 & \leq q_{5} \leq 0.281 \\
-0.1561 & \leq q_{6} \leq 0.1561
\end{aligned}
$$

In addition, the maximum frequency deviation at maximum power is limited using non-linear inequality constraint equation as defined by (16).

$$
p_{\max } \cdot k_{f 1} \cdot k_{f 2}-\Delta \omega_{\max }\left(k_{f 1}+k_{f 2}\right)<0
$$

\subsection{Objective Functions}

The objective function defines the criteria of finding the best solution from all feasible solutions of an optimization problem. Multiple objective functions 
can also be applied for optimal solution. However, simultaneously optimizing each objective functions may not lead to a single solution for non-trivial multi-objective optimization problem. In that case, objective functions are said to be conflicting and the solution of the system cannot be found without degrading the objective values. A trade-off is required between the functions in order to obtain a favorable solution. The simplest approach to achieve the trade-off among the objective functions is a weighted sum method. In weighted sum method, a single function is formulated by multiplying each objective function with a predefined weighting factor as expressed by (17). The weighting factor defines the relative magnitude of each function in the overall solution. Pareto Front analysis of the objective functions can then be applied to choose the optimal operating points and the best solution.

$$
\begin{gathered}
\min \{F(x)\} \\
F(x)=\sum_{m=1}^{h} \gamma_{m} f_{m}(x) \quad \gamma_{m} \in[0,1]
\end{gathered}
$$

Here, $\gamma_{m}$ is the weight of the $m^{\text {th }}$ objective function. In general, the weights are selected to satisfy (18).

$$
\sum_{m=1}^{h} \gamma_{m}=1
$$

An objective function can either be a loss function or profit function but all objectives must be converted into one type for weighted sum method. In the presented study, two objective functions are selected for the optimization problem as expressed by (19).

$$
\begin{gathered}
\min \{f(p, v, \gamma)\} \\
f(p, v, \gamma)=\gamma \cdot f_{l}(p)+(1-\gamma) \cdot f_{v}(v)
\end{gathered}
$$

Here, $f_{l}(p)$ is an objective function to minimize active loss, and $f_{v}(v)$ is an objective function for minimizing voltage deviation in an offshore network.

\subsubsection{Minimizing Active Power Losses}

The active losses minimization objective function is given in (20). It is defined as the sum of total wind active power and the net active power received at the onshore grids. The function is expressed as least square error of the network active power losses.

$$
f_{l}(p)=\left(p_{3}+p_{4}+p_{5}+p_{6}+p_{\text {grid_A }}+p_{\text {grid_B } B}\right)^{2}
$$




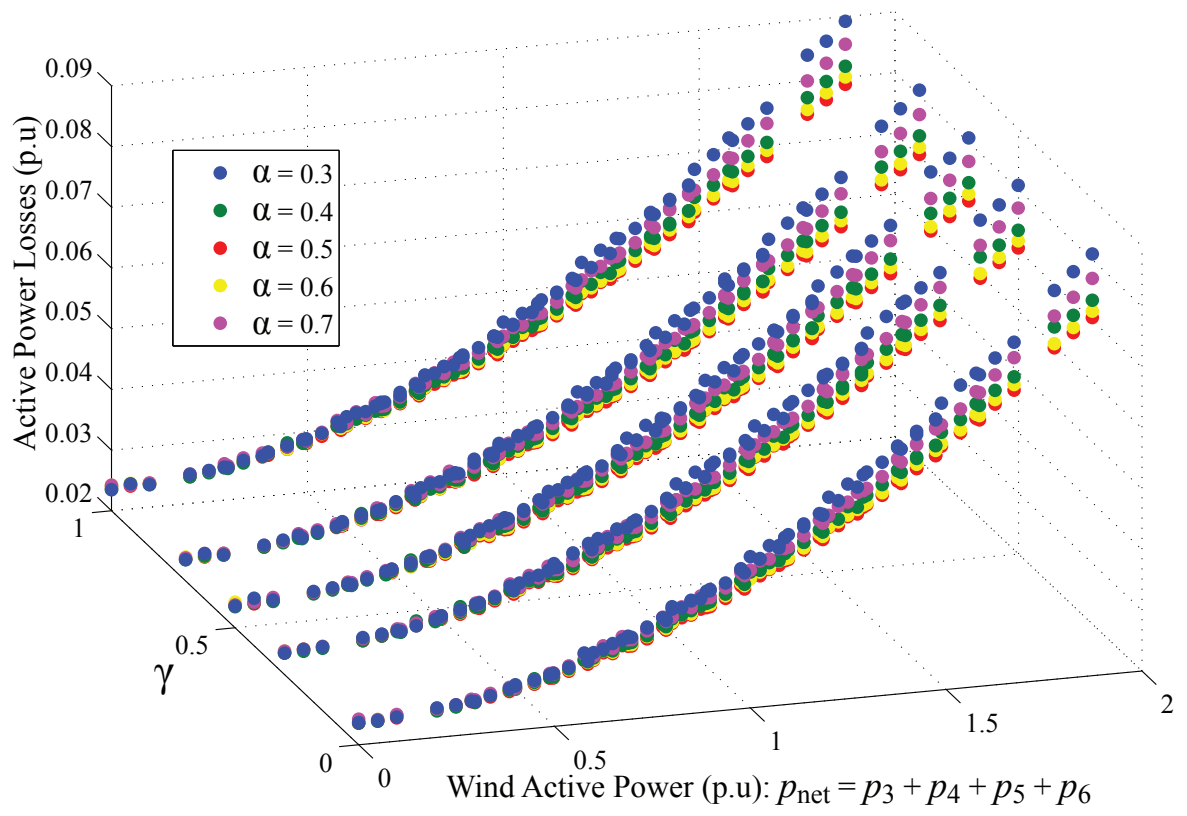

Figure 4: Total active power losses of the system.

Here, $p_{3}, p_{4}, p_{5}$, and $p_{6}$ are the active power of wind power plants $\mathrm{A}, \mathrm{B}, \mathrm{C}$, and $\mathrm{D}$ respectively. The active powers received at onshore grids of countries $\mathrm{A}$ and $\mathrm{B}$ are referred as $p_{g r i d_{-} A}, p_{g r i d_{-} B}$ respectively. The full weight to this objective function is given at $\gamma=1$.

\subsubsection{Minimizing Voltage Deviation}

An objective function to minimize the least square voltage deviation is given in (21) in p.u system.

$$
f_{v}(v)=\sum_{i=1}^{n}\left(u_{i}-1.0\right)^{2}
$$

Here, $u_{i}$ is the voltage magnitude of $i^{\text {th }}$ bus. The full weight to this objective function is given at $\gamma=0$.

\section{System Analysis}

The solution of the optimization algorithm provides the optimum operating values of the wind generation and the VSC-HVDC systems which 


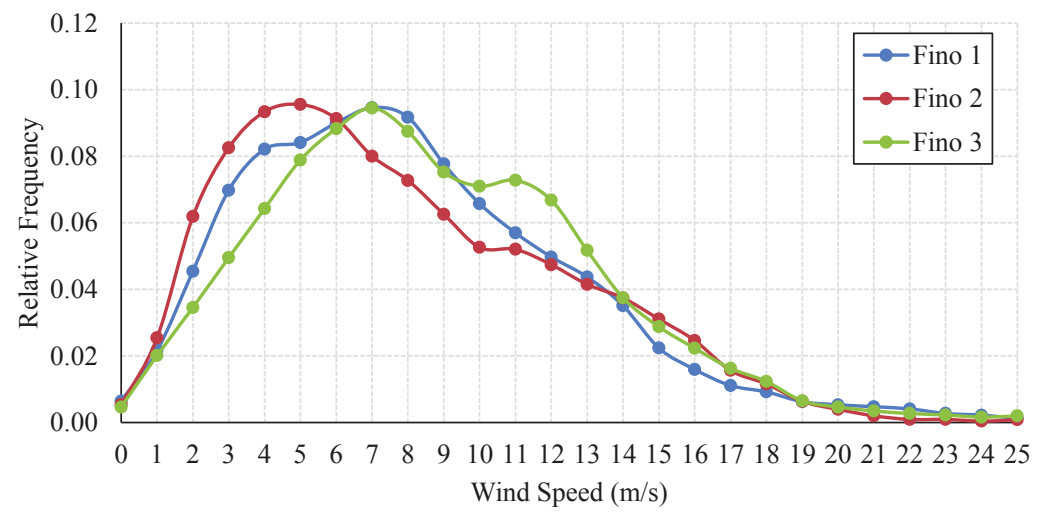

Figure 5: Wind profile according to the FINO 1, 2, and 3 database of the year 2016.

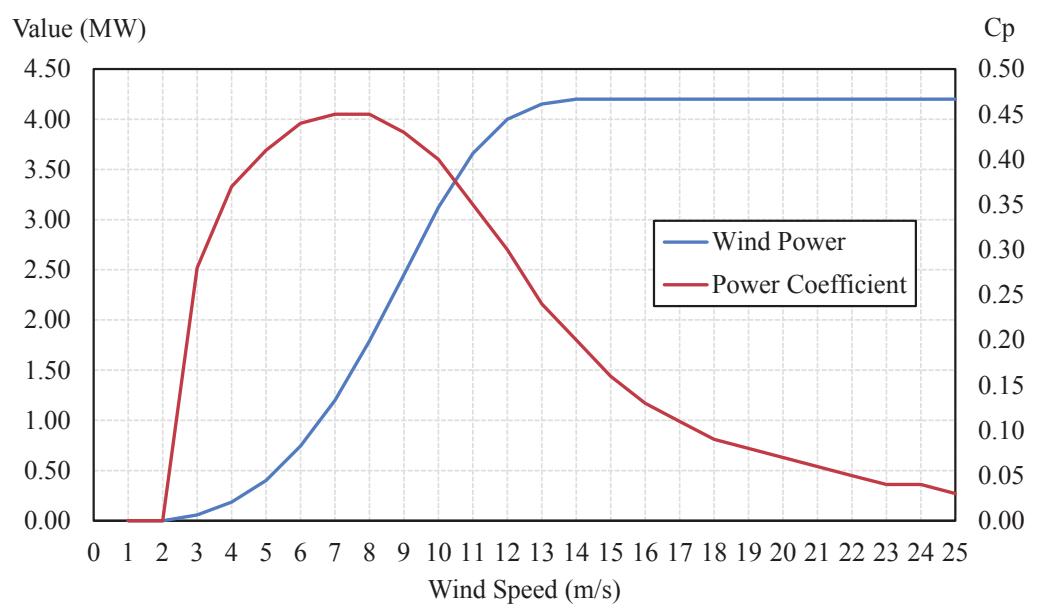

Figure 6: ENERCON wind turbine E-126-EP4 power curve.

consists of the voltage and frequency droop gains, the reactive power support by each wind farms, and the VSC-HVDC reactive power sharing factor. The optimum operating values are found with respect of the wind active power in-feed and the VSC-HVDC active power sharing factor. The network is optimized with respect to the total active losses in the network and the bus voltage deviation from its rated value.

In Fig. 4, the total active power losses of the $\mathrm{AC}$ and $\mathrm{DC}$ network is shown with respect of objective weight factor and active power sharing factor. The plot illustrate the network losses over the range of wind active power from zero to maximum. The wind powers are the inputs of the OPF algorithm 


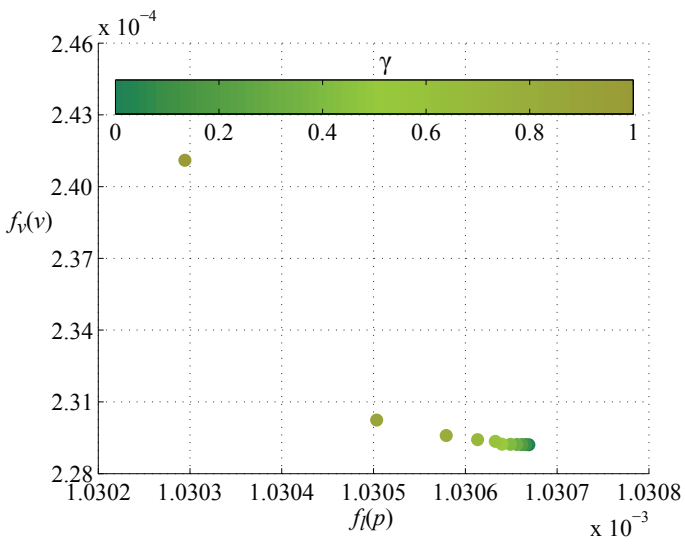

(a) $\alpha=0.5$, and $p_{\text {net }}=0.688 \mathrm{p} . \mathrm{u}$

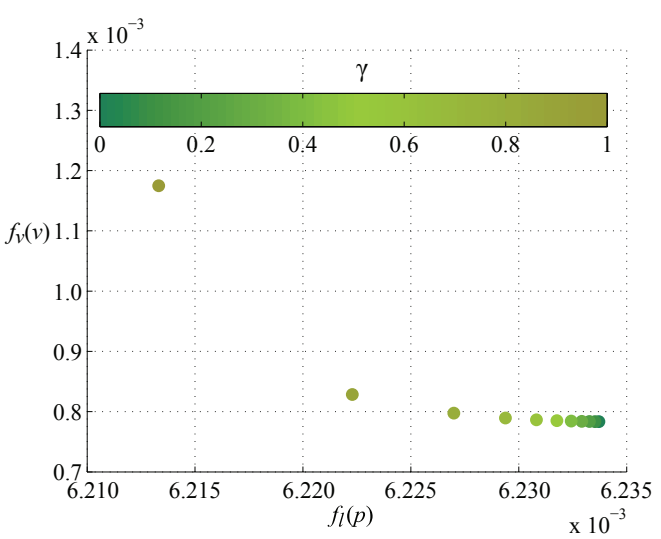

(b) $\alpha=0.5$, and $p_{\text {net }}=1.8753 \mathrm{p} . \mathrm{u}$

Figure 7: Pareto front analysis of multi-objective functions.

and it is executed over the range of wind power by first changing WF-A power from zero to maximum, and then increasing WF-B power up to maximum power while keeping WF-A power fixed to maximum value. And then increasing WF-C power and so on. In the results, the scale of wind power is defined as cumulative power refer as $p_{\text {net }}$ at each steps. According to the results, the active power loss variation is relatively low with respect of the objective function weight factor. The difference in active power loss with respect to the power sharing factor can be observed at high wind in-feed i.e the minimum losses in the network is at $\alpha=0.5$. Since the large wind capacity is installed near country $\mathrm{B}$, therefore the network produce high active losses at $\alpha=0.3$. The average power in-feed by the wind farms into the offshore AC network is calculated using wind profile of FINO database [35]. FINO is a research project started in 2002 having funding support by Federal Ministry for the Environment, Nature, Conservation, Building and Nuclear Safety (BMU) of Germany. The database provide meteorological and oceanographic measurement made at three research platforms in the North and Baltic Seas. The wind profile of FINO 1,2 and 3 are shown in Fig. 5 over the period of one year. By considering FINO 1 wind profile for wind farm $\mathrm{C}$ and $\mathrm{D}$, the average wind speed of $8 \mathrm{~m} / \mathrm{s}$ is considered for both wind farms. FINO 2 wind profile is considered for wind farm A which give the wind speed of $5 \mathrm{~m} / \mathrm{s}$. And, the wind speed of $7 \mathrm{~m} / \mathrm{s}$ is assumed for wind farm B by considering FINO 3 wind profile. By considering the power curve of ENERCON wind turbine E-126-EP4 given in Fig. 6 for all wind farms, the most frequent 


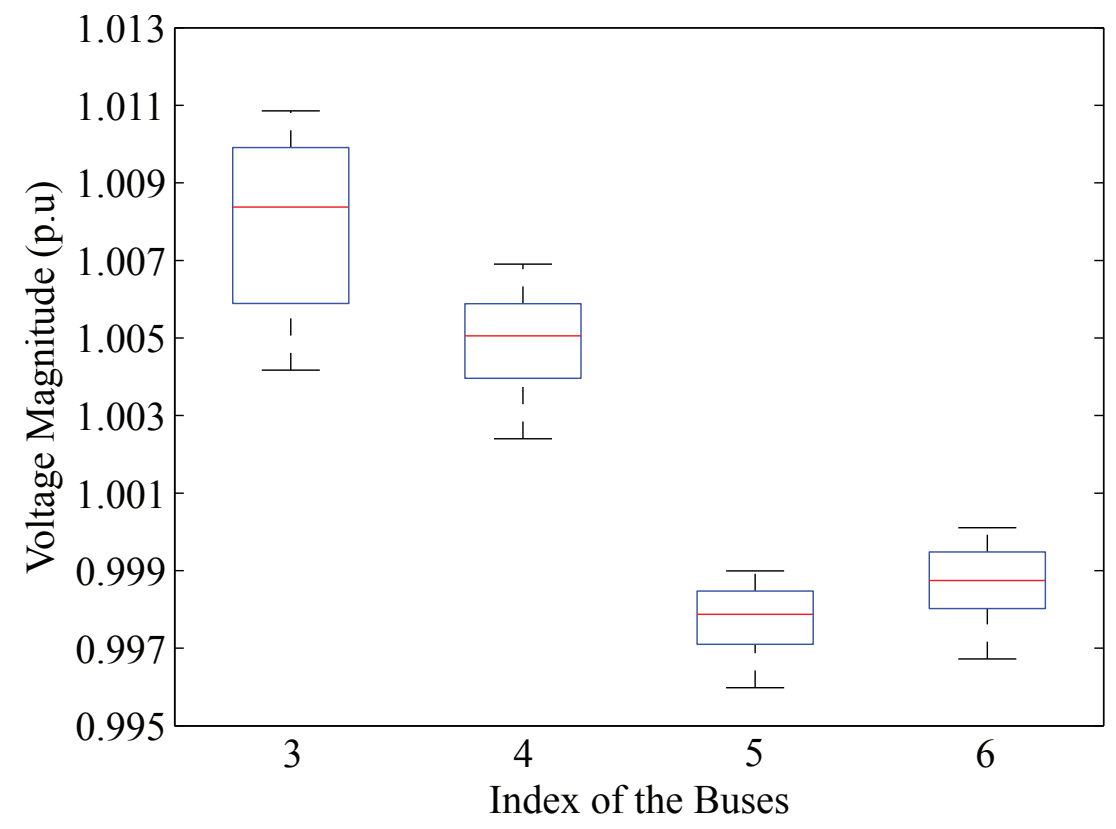

Figure 8: Busbar voltage level probability at $\gamma=0.0$, and $\alpha=0.5$.

active power available in the offshore AC network is calculated as 0.688 p.u [36]. The profile is applied to compare the Pareto Front analysis at average and maximum wind production.

The Pareto Front analysis has been shown in Fig. 7a to illustrate the best optimum solution with respect to the objective functions weighted factor $(\gamma)$. The weighted factor apply the trade-off criteria between the active power losses and the network voltages deviations for the optimal solution selection. The Pareto Front has been generated at $\alpha=0.5$ and the net active power of 0.688 p.u. It is clear from the result that the minimum active losses is achieved at $\gamma=1.0$, and the best optimum voltage level is achieved at $\gamma=0.0$. However, the improvement in the active losses is low over the range of $\gamma$ i.e the improvement factor is approximately $0.5 \times 10^{-6}$ whereas the improvement factor in the voltage is approximately $13.0 \times 10^{-6}$. In order to determine the optimum operating point, higher weighting can be given to voltage optimization objective function as a trade-off. The Pareto Front at the maximum capacity has been shown in Fig. 7b. At high wind power penetration, relatively high reactive power is required to minimize the active losses which increases the voltage deviation in the network. At high power, the active power loss improvement factor is approx $21.0 \times 10^{-6}$, and the voltage 


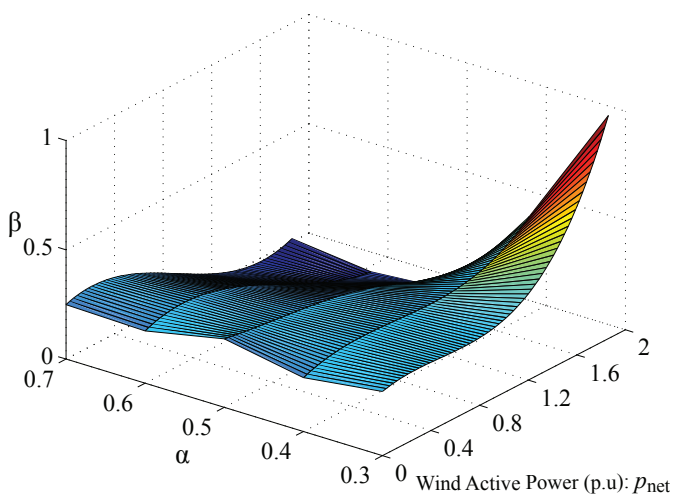

(a) $\gamma=0.0$

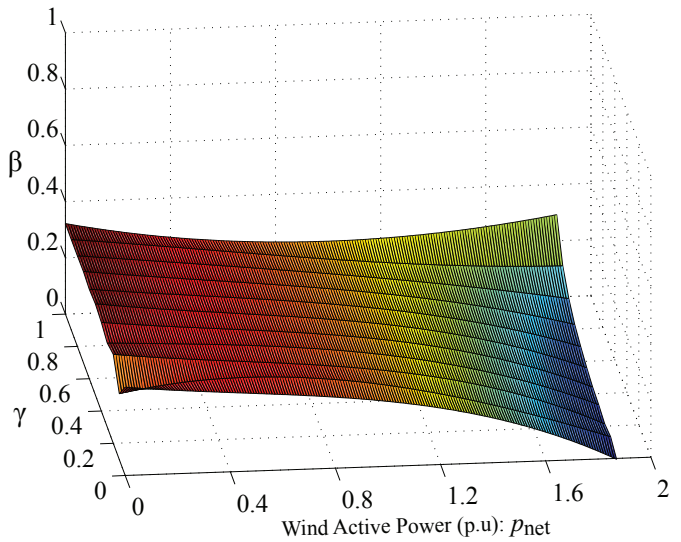

(b) $\alpha=0.5$

Figure 9: Optimum values of reactive power sharing.

improvement factor is $0.4 \times 10^{-3}$. The effect of objective weighting factor on the improvement of the voltage and the power loss is relatively more at high energy in the offshore network. The comparison conclude that the reasonable trade-off can be achieved between the objective functions at $\gamma=0.9$. Note that the optimum solution also depend on $\alpha$ which is the energy export factor defined by the transmission operators.

The network voltages deviation probability are shown in Fig. 8 at $\alpha=0.5$ and $\gamma=0.0$. In this condition, the full weight is given to voltage minimization function in order to observe the least voltage deviation in the network. The probability plots can be analyzed for other conditions using similar method. According to the result, the maximum voltage deviation will occur at busbar 3 with $50 \%$ probability of having voltages between 1.010 p.u and 1.006 p.u. The minimum voltage deviation will occur at busbar 5 having $50 \%$ probability to be in the voltage range of 0.998 p.u and 0.997 p.u. The results shows that the voltages are within the required operating range.

To achieve the minimum loss, reactive power sharing $(\beta)$ between converters must also be optimally chosen. The response of $\beta$ with respect to the wind power in-feed and $\alpha$ is shown in Fig. 9a. Here, the weighting factor is assigned to $\gamma=0.0$. It is clear that more reactive power contribution is required by the VSC-2 when the large power is transferred to the country A at high wind penetration. Furthermore, the VSC-2 need to have more reactive power compared to $\mathrm{VSC}-1$ for $\alpha<0.5$ and almost all of the reactive power must be provided by VSC- 1 at $\alpha=0.7$, when the net wind power is 


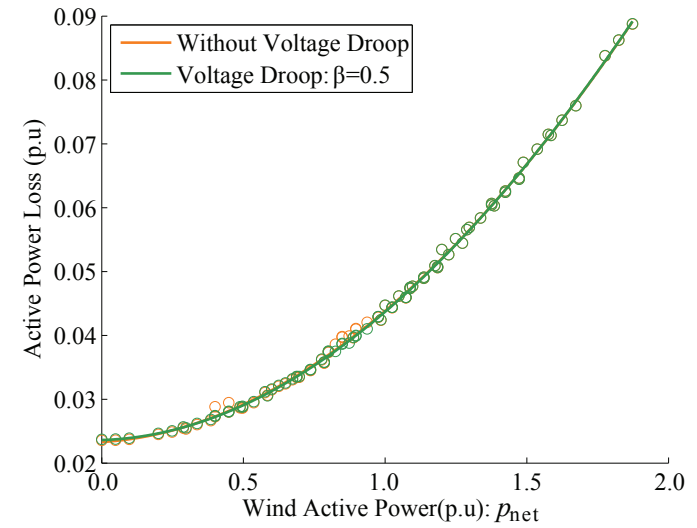

(a)

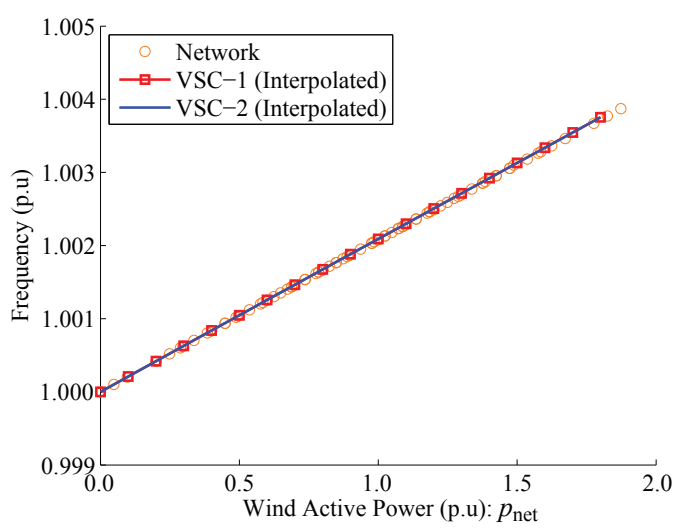

(b)

Figure 10: Active power losses and frequency response of the offshore AC network at $\alpha=0.3$ and $\gamma=1.0$.

greater than 1.0 p.u. On the other hand, the reactive power sharing factor is approximately 0.3 up to 1.0 p.u net wind power.

The influence of the weighting factor on the $\beta$ can be observed from Fig. $9 \mathrm{~b}$ for $\alpha=0.5$. It can be seen that the $\beta$ is relatively constant with respect of $\gamma$ and changes mainly with respect of wind power. Indeed, the affect of $\gamma$ on the minimization of two objective function is significant at high power. It can be seen that more contribution is required from the VSC1 at high wind power in order to minimize the voltage deviation.

The comparison of the active power losses with and without voltage droop schemes is shown in Fig. 10a. No voltage droop schemes means that both offshore converters of VSC-HVDC transmission system are controlling the bus voltages at the fixed set-points i.e $1.0 \mathrm{p} . \mathrm{u}$, and the reactive power flow depends on the network impedance and the actual amount of active power flowing through them. Thus, it is not possible to control the contribution of each VSCs reactive power. The response shows that the active power losses are same in both case however the application of the voltage droop provide additional degree to control the reactive power sharing of the VSCs. The transmission operator can additionally optimize the cost with the control over reactive power contribution. The steady-state frequencies response are shown in Fig. 10b. It is clear that the frequencies imposed by both VSCs are same and the maximum frequency deviation in the system does not exceed the limit i.e the maximum frequency deviation is $50.19 \mathrm{~Hz}$ at $1.873 \mathrm{p} . \mathrm{u}$ wind power. Note that here the active power sharing is 0.3 and objective weighting 


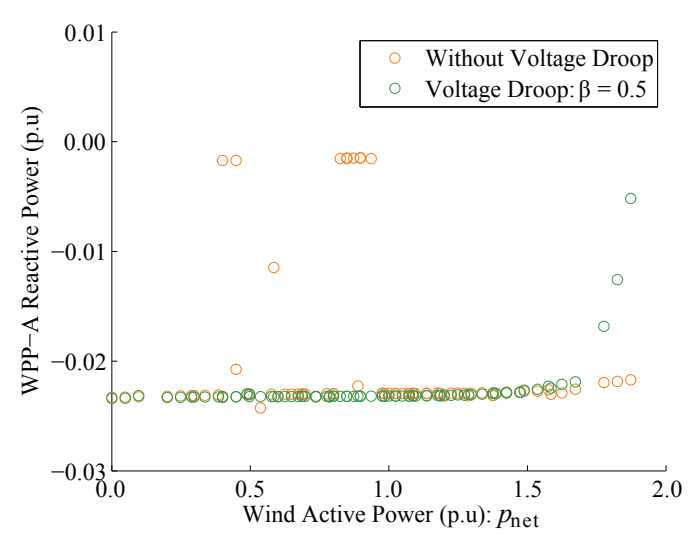

(a)

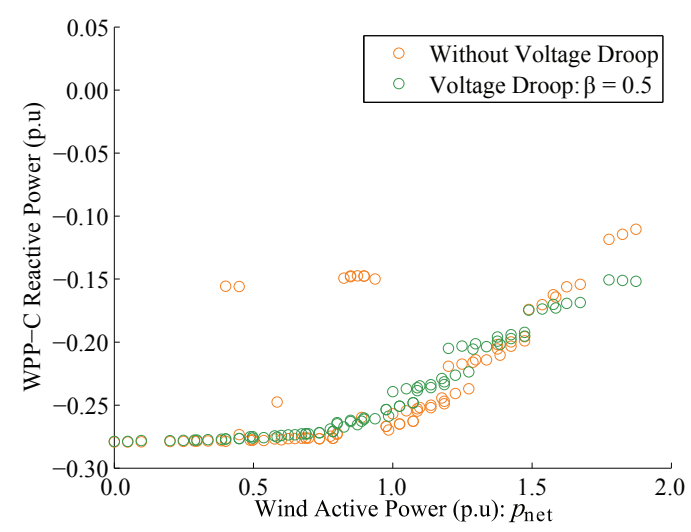

(c)

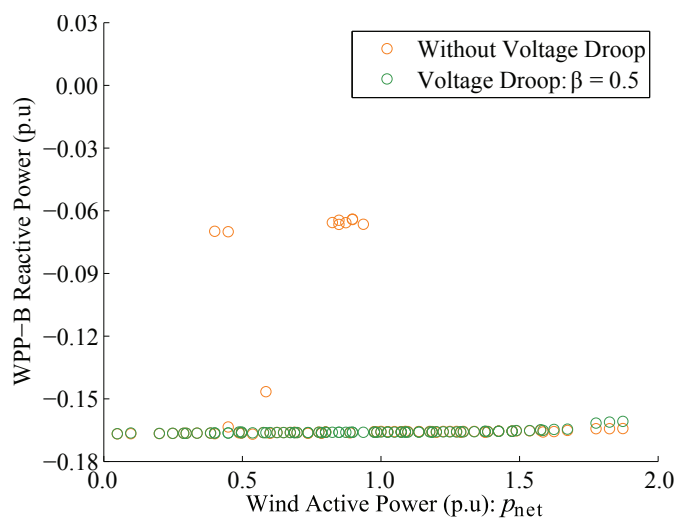

(b)

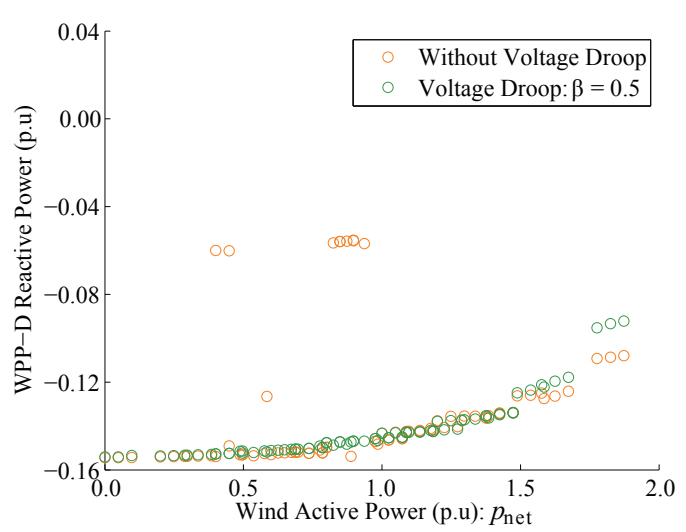

(d)

Figure 11: Reactive power support by the wind farms at $\alpha=0.3$, and $\gamma=1.0$.

factor is 1.0 and the calculated frequency droop gains of VSC-1 and VSC-2 are $k_{f 1}=0.0030 \mathrm{p} . \mathrm{u}$, and $k_{f 2}=0.0070$ p.u respectively.

Furthermore, the difference in with and without voltage droop schemes can be seen from the reactive power support provided by the wind farms. The optimum reactive power points of the wind generation system are shown in Fig. 11a, Fig. 11b, Fig. 11c, and Fig. 11d at $\alpha=0.3$ equal and $\gamma=1.0$. An offshore network has relatively high cable capacitance which requires wind turbine to absorb this power to minimize the voltage deviation. Without voltage droop scheme, reactive power operating point of the wind turbines requires to be set with respect of the variation of VSCs reactive power. The VSC reactive power variation is then mainly influence by the impedance of the network and active power flow. This can be observed by the reactive 


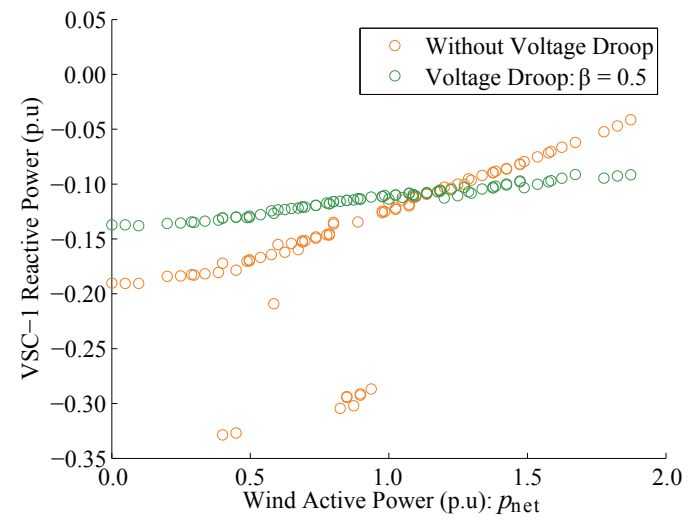

(a)

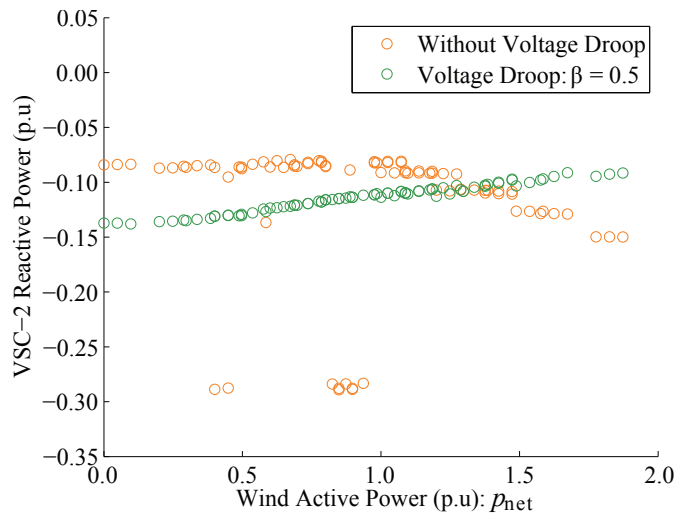

(b)

Figure 12: Reactive power support by VSC-HVDC system at $\alpha=0.3$, and $\gamma=1.0$.

power response of the VSC-1 and VSC-2 as shown in Fig 12a, and Fig. 12b.

It can be observed that the reactive power of VSC-1 and VSC-2 are not equal, and their sharing is uncontrollable without voltage droop scheme. One converter flow more reactive power than other and some of the reactive power operating points are near to their limits, consequently reactive power operating point of wind farms are influenced. On the other hand, reactive power flow is consistent and equally shared by both VSC-HVDC transmission system using voltage droop scheme. The voltage droop scheme provide better controlled of reactive power control in the offshore AC network, and they are well within the limits. The desired reactive power contribution by each VSCs can be assigned by setting voltage and frequency droop gains value acquire through optimization algorithm. For the studied system, the voltage droop gains at $\alpha=0.3, \beta=0.5$, and $\gamma=1.0$ are found as $k_{u 1}=-0.0446 \mathrm{p} . \mathrm{u}$, and $k_{u 2}=0.0451$ p.u.

\section{Conclusion}

Large offshore wind farms installation at North Sea will make future European energy efficient and affordable. The concept of offshore AC network enables the integration of such high wind energy generation with the onshore grids. In this paper, the control scheme of grid forming voltage source converters is proposed for an offshore AC network that has multiple VSC-HVDC transmission systems. It has been demonstrated that the VSCs controls the power flow using droop scheme which provides additional degree 
of freedom to manage power losses and busbar voltages in the network. The optimum operating points can be calculated using multi-objective optimization algorithm which enable the selection of different criteria according to the operational requirements. Furthermore, a method of selecting frequency and voltage droop gains according to power sharing criteria has been presented. It is analyzed that the application of the droop gains can cause the long-term voltage instability in the network. A new voltage droop gain selection criteria has been proposed which ensure the network stability. The presented paper address the key issue of optimal use of offshore wind energy resources and it propose the method of optimal operation of the offshore network that can be applied to study the feasibility of future offshore wind power plant projects.

\section{Acknowledgments}

The research leading to these results has received funding from the People Programme (Marie Curie Actions) of the European Unions Seventh Framework Programme (FP7/2007-2013) under REA grant agreement n317221.

\section{References}

[1] X. Zhang, C. Ma, X. Song, Y. Zhou, W. Chen, The impacts of wind technology advancement on future global energy, Applied Energy 184 (2016) 1033-1037. doi:10.1016/j.apenergy.2016.04.029.

[2] I. Pineda, K. Ruby, A. Ho, A. Mbistrova, G. Corbetta, The European offshore wind inductry: key trends and statistics 1st half 2016, Tech. rep., European Wind Energy Association (july 2016).

[3] P. Bresesti, W. L. Kling, R. L. Hendriks, R. Vailati, HVDC Connection of Offshore Wind Farms to the Transmission System, IEEE Transactions on Energy Conversion 22 (1) (2007) 37-43. doi:10.1109/TEC.2006.889624.

[4] C. Trujillo, D. Velasco, J. Guarnizo, N. Díaz, Design and implementation of a VSC for interconnection with power grids, using the method of identification the system through state space for the calculation of controllers, Applied Energy 88 (9) (2011) 3169-3175. doi:10.1016/j.apenergy.2011.02.038. 
[5] C. Humpert, Long distance transmission systems for the future electricity supply Analysis of possibilities and restrictions, Energy 48 (1) (2012) 278-283. doi:10.1016/j.energy.2012.06.018.

[6] E. Pican, E. Omerdic, D. Toal, M. Leahy, Analysis of parallel connected synchronous generators in a novel offshore wind farm model, Energy 36 (11) (2011) 6387-6397. doi:10.1016/j.energy.2011.09.035.

[7] O. Gomis-Bellmunt, A. Junyent-Ferré, A. Sumper, S. Galceran-Arellano, Maximum generation power evaluation of variable frequency offshore wind farms when connected to a single power converter, Applied Energy 87 (10) (2010) 3103-3109. doi:10.1016/j.apenergy.2010.04.025.

[8] M. De Prada Gil, O. Gomis-Bellmunt, A. Sumper, Technical and economic assessment of offshore wind power plants based on variable frequency operation of clusters with a single power converter, Applied Energy 125 (2014) 218-229. doi:10.1016/j.apenergy.2014.03.031.

[9] S. T. Schroder, P. Meibom, S. Spiecker, C. Weber, Market impact of an offshore grid: A case study, in: IEEE PES General Meeting, IEEE, 2010, pp. 1-5. doi:10.1109/PES.2010.5590044.

[10] Tennet-News, TenneT presents Hub and Spoke concept for large scale wind energy on the North Sea (2016).

URL https://www.tennet.eu/news/detail/tennet-presentshub-and-spoke-concept-for-large-scale-wind-energy-on-thenorth-sea/

[11] P. Sandeberg, P. Moran, A. Lomardi, A. Hernandez, C. Feltes, D. Ramsay, Special considerations for ac collector systems and substations associated with hvdc connected wind power plants, Tech. Rep. March, CIGRE WG B3.36 (2015).

[12] O. Gomis-Bellmunt, J. Liang, J. Ekanayake, R. King, N. Jenkins, Topologies of multiterminal HVDC VSC transmission for large offshore wind farms, Electric Power Systems Research 81 (2011) 271-281. doi:10.1016/j.epsr.2010.09.006.

[13] M. Aragüés-Peñalba, A. Egea-Àlvarez, S. G. Arellano, O. GomisBellmunt, Droop control for loss minimization in HVDC multi-terminal 
transmission systems for large offshore wind farms, Electric Power Systems Research 112 (2014) 48-55. doi:10.1016/j.epsr.2014.03.013.

[14] M. Raza, O. Gomis-Bellmunt, Control system of voltage source converter to interconnect offshore ac hub with multiple onshore grids, in: 2015 International Conference on Renewable Energy Research and Applications (ICRERA), IEEE, Palermo, 2015, pp. 677-682. doi:10.1109/ICRERA.2015.7418497.

[15] J. De-Decker, J. Tambke, J. Volker, K. Michalowska-Knap, An offshore transmission grid for wind power integration: The European technoeconomic study OffshoreGrid, in: IEEE PES General Meeting, IEEE, 2010, pp. 1-8. doi:10.1109/PES.2010.5589887.

[16] E. A. A. Coelho, P. C. Cortizo, P. F. D. Garcia, Small signal stability for parallel connected inverters in stand alone ac supply systems, IEEE Transactions on Industry Applications 38 (2) (2002) 533-542. doi:10.1109/28.993176.

[17] C. K. Sao, P. W. Lehn, Autonomous load sharing of voltage source converters, IEEE Transactions on Power Delivery 20 (2) (2005) 1009 1016. doi:10.1109/TPWRD.2004.838638.

[18] T. B. Lazzarin, G. A. T. Bauer, I. Barbi, A control strategy for parallel operation of single phase voltage source inverters: analysis, design, and experimental results, IEEE Transactions on Industrial Electronics 60 (6) (2013) 2194-2204. doi:10.1109/TIE.2012.2193856.

[19] M. Raza, E. Prieto-Araujo, O. Gomis-Bellmunt, Small Signal Stability Analysis of Offshore AC Network having Multiple VSCHVDC System, IEEE Transactions on Power Delivery (2017) 11doi:10.1109/TPWRD.2017.2725982.

[20] I. Erlich, W. Nakawiro, M. M. Rojas, Optimal dispatch of reactive sources in wind farms, in: 2011 IEEE Power and Energy Society General Meeting, IEEE, 2011, pp. 1-7. doi:10.1109/PES.2011.6039534.

[21] M. Martinez-Rojas, A. Sumper, O. Gomis-Bellmunt, A. Sudrià-Andreu, Reactive power dispatch in wind farms using particle swarm optimization technique and feasible solutions search, Applied Energy 88 (12) (2011) 4678-4686. doi:10.1016/j.apenergy.2011.06.010. 
[22] H. Kim, M. Kim, Optimal generation rescheduling for meshed AC/HIS grids with multi-terminal voltage source converter high voltage direct current and battery energy storage system, Energy 119 (2017) 309-321. doi:10.1016/j.energy.2016.11.108.

[23] M. Alonso, H. Amaris, C. Alvarez-Ortega, A multiobjective approach for reactive power planning in networks with wind power generation, Renewable Energy 37 (1) (2012) 180-191. doi:10.1016/j.renene.2011.06.021.

[24] J. Zheng, J. Chen, Q. Wu, Z. Jing, Multi-objective optimization and decision making for power dispatch of a large-scale integrated energy system with distributed DHCs embedded, Applied Energy 154 (2015) 369-379. doi:10.1016/j.apenergy.2015.05.023.

[25] H. V. Pham, J. L. Rueda, I. Erlich, Online Optimal Control of Reactive Sources in Wind Power Plants, IEEE Transactions on Sustainable Energy 5 (2) (2014) 608-616. doi:10.1109/TSTE.2013.2272586.

[26] A. Rabiee, M. Vanouni, M. Parniani, Optimal reactive power dispatch for improving voltage stability margin using a local voltage stability index, Energy Conversion and Management 59 (2012) 66-73. doi:10.1016/j.enconman.2012.02.017.

[27] J. W. Bialek, European offshore power grid demonstration projects, in: 2012 IEEE Power and Energy Society General Meeting, IEEE, 2012, pp. 1-6. doi:10.1109/PESGM.2012.6345283.

[28] M. Raza, K. Schönleber, O. Gomis-Bellmunt, Droop Control Design of Multi-VSC Systems for Offshore Networks to Integrate Wind Energy, Energies 9 (10) (2016) 826. doi:10.3390/en9100826.

[29] M. Raza, C. Collados, O. Gomis-Bellmunt, Reactive power management in an offshore $\mathrm{AC}$ network having multiple voltage source converters, in: 2016 IEEE 16th International Conference on Environment and Electrical Engineering (EEEIC), IEEE, 2016, pp. 1-7. doi:10.1109/EEEIC.2016.7555714.

[30] ABB, XLPE submarine cable systems.

[31] Nexans, Nexans Submarine Power Cables (2013). 
[32] M. Raza, O. Gomis-Bellmunt, Control design strategy to enhance fault right through capability of vsc hvdc transmission system interconnecting offshore wind power plant, in: European Wind Energy Association Annual Conference EWEA 2015, EWEA, Paris, 2015, pp. 1-10.

[33] J. Beerten, S. Cole, R. Belmans, Generalized steady-state vsc mtdc model for sequential ac/dc power flow algorithms, IEEE Transactions on Power Systems 27 (2) (2012) 821-829. doi:10.1109/TPWRS.2011.2177867.

[34] Tennet, Requirements for Offshore Grid Connections in the Grid of TenneT TSO GmbH (2012).

[35] Federal Ministry for Economic Affairs and Energy (BMWi), and Project Executing Organization (PTJ), Wind Speed Data (FINO Databank), accessed on 23-03-2017 (2017).

URL http://fino.bsh.de/

[36] ENERCON, ENERCON Product Overview, accessed on 23-03-2017 (2017).

URL http://www.enercon.de/en/home/ 